\title{
BMJ Open Migrants Examined for Determinants of psychopathology through INternet Assessment (MEDINA) study: a cross-sectional study among visitors of an Internet community
}

\author{
Madelien Hermina van de Beek, Lian van der Krieke, Robert Anton Schoevers
}

To cite: van de Beek MH, van der Krieke L,

Schoevers RA. Migrants

Examined for Determinants of psychopathology through INternet Assessment (MEDINA) study:

a cross-sectional study among visitors of an Internet community. BMJ Open 2014;4:e003980.

doi:10.1136/bmjopen-2013003980

- Prepublication history for this paper is available online. To view these files please visit the journal online (http://dx.doi.org/10.1136/ bmjopen-2013-003980)

Received 8 September 2013 Revised 30 November 2013 Accepted 4 December 2013

CrossMark

Department of Psychiatry, University of Groningen, University Medical Center Groningen, Groningen, The Netherlands

Correspondence to Madelien van de Beek; m.vandebeek@dimence.nl

\begin{abstract}
Introduction: Migration is a risk factor for the onset of psychopathology. A range of social factors may play a role in the aetiology of psychiatric disorders in migrants. $A$ better understanding of these associations is needed to develop preventive interventions to reduce the disease burden in the migrant population. Research among minority groups is generally time consuming and it is difficult to recruit participants. Internet can offer interesting new possibilities to conduct research among ethnic minorities. This article describes the design of an epidemiological study in the MoroccanDutch population, which will be entirely performed online. We investigate the association between social factors and psychopathology.
\end{abstract}

Methods and analysis: The website Marokko.nl is visited by $70 \%$ of the young Moroccan-Dutch population in the Netherlands. This website therefore provides a unique possibility for research within this population. We will conduct a survey with online questionnaires via this website. The online survey consists of several validated short self-report questionnaires, measuring depressive and anxiety symptoms (The Kessler Psychological Distress Scale (K10)), psychotic symptoms (The Prodromal Questionnaire-16 (PQ-16)) and instruments measuring discrimination, social support and social defeat. Furthermore, demographic characteristics are collected. We will use univariate and multivariate methods for analysing the data.

Ethics and dissemination: The local medical ethical committee has assessed the study protocol and judged that the study could be conducted without their approval. Knowledge dissemination will take place through peer-reviewed publication in scientific journals as well as publication for participants on the project website.

Discussion: In this study we further explore the association between psychopathology and social factors within an online Moroccan-Dutch sample. The recruitment of participants via the website Marokko.nl creates a big advantage in collecting a large sample of a specific migrant population. Strengths and limitations of the methodology are discussed. Furthermore, we

\section{Strengths and limitations of this study}

- This study uses a novel methodology, in which recruitment and data collection are performed entirely online.

- The use of the Internet creates the opportunity to recruit many Moroccan-Dutch migrants, a population which is otherwise difficult to reach for research.

- We collaborate with the gatekeepers of the website Marokko.nl, which is visited by $70 \%$ of the young Moroccan-Dutch population in the Netherlands.

- Because of Internet recruitment, we collect a convenience sample with the risk of selection bias.

- Owing to the cross-sectional design, we cannot determine the direction of associations between variables that we investigate.

review the advantages and challenges of online epidemiological research methods.

\section{INTRODUCTION}

Across countries and cultures, migration is a risk factor for the development of psychopathology. ${ }^{1}$ Psychiatric disorders are heterogeneous and they develop as a result of the interplay between a range of genetic and environmental influences. ${ }^{2-4}$ Gaining a better understanding of the aetiology of psychopathology, and especially of modifiable risk factors that are associated with its development, is essential because this can lead us to preventive interventions. In migrants, some aetiological risk factors remain unchanged (eg, genetic factors) whereas others (eg, environmental factors) may change as a result of migration. Studying the 
development of psychopathology in migrant populations may further increase our understanding of the role of these risk factors. ${ }^{5}$

Currently available evidence suggests that the association between migration and psychopathology is the strongest for psychotic disorders. Two meta-analyses found that the relative risk (RR) for developing schizophrenia was significantly higher in the migrant population compared with the native population. ${ }^{6} \quad 7$ Interestingly, the RR for developing schizophrenia greatly differed between migrant subgroups, and was as high as 4.5 for second-generation migrants and 4.8 in black ethnic groups. ${ }^{7-9}$ For mood disorders, Swinnen and Selten ${ }^{10}$ found a RR of 1.38 (95\% CI 1.17 to 1.62 ) for migrants in a meta-analysis covering 14 studies (2 on depressive disorder, 5 on bipolar disorder and 9 on mood disorders of unspecified polarity). Since then, other studies have confirmed the increased prevalence of depressive symptoms in migrant populations. ${ }^{11}{ }^{12}$ A recent study by Cantor-Graae and Pedersen has shown increased incidence of risk ratios for all psychiatric disorders in foreign-born adoptees and in second-generation migrants having one foreign-born parent. However, for first-generation and second-generation migrants with two foreign-born parents, the risk was only increased for schizophrenia. ${ }^{1}$

Variation in the incidence of psychopathology between different ethnic groups has also been shown in the Netherlands, where the present study is situated. In 2012, the largest migrant groups in the Netherlands (16.7 million inhabitants) originated from Turkey (392 923; 2.3\% of the total population), Morocco (362 954; $2.2 \%$ of the total population), Surinam (346 797; $2.1 \%$ of the total population) and the Dutch Antilles (143992; $0.9 \%$ of the total population). ${ }^{13}$ For schizophrenia, the incidence was increased in most of the different migrant groups in the Netherlands compared with the overall population, but not in all. The incidence of schizophrenia appeared to be highest in the second-generation Moroccan-Dutch inhabitants. ${ }^{14} 15$ Furthermore, a Dutch study has shown that incidence and prevalence rates of mood disorders are the highest among Turkish migrants (RR 4.9), followed by Moroccan migrants (RR 3.6) and Surinamese migrants (RR 1.8), while the rates in Western-European migrants were comparable to the general Dutch population. ${ }^{16}$ These findings replicate the results from a previous Dutch study. ${ }^{17}$

\section{Possible explanations}

Although migrants are at increased risk to develop psychopathology, the explanation for this association is still largely unknown. Previously, it was hypothesised that the disorder itself would be a factor in migration, because especially schizophrenia and bipolar patients were believed to be more restless and rootless and therefore more inclined to migrate. This 'selective migration' hypothesis was first suggested by $\varnothing$ degaard ${ }^{18}$ in 1932 but is now generally discarded, as the scientific evidence cannot support it. ${ }^{19} \quad 20$ An example of an argument against the selective migration theory is the fact that the incidence of schizophrenia in second-generation migrants is substantially higher compared with their parents from the first generation. This phenomenon points to the importance of postmigration factors or, in other words, (social) factors in the country of destination. ${ }^{6}$ Social factors that are frequently suggested to be associated with psychopathology in migrants are (among others): discrimination, lack of social support and social defeat. Discrimination was associated with psychotic symptoms in several studies. ${ }^{21-23}$ Also in mood disorders, an association with discrimination was found. ${ }^{23-26}$ Lack of social support or isolation was found to be associated with psychopathology in several studies. ${ }^{27}{ }^{28}$ In the original article by Gilbert and Allan ${ }^{29}$ in 1998, the concept of social defeat, or 'being in a subordinate position" 9 was associated with depression. Social defeat has also been hypothesised as an aetiological factor for developing schizophrenia in migrant populations. ${ }^{9}$ Discrimination, social support and social defeat are variables we will measure in this study. Furthermore, associations between demographic variables and increased risk for psychopathology in migrants have also been found. As an example, younger age at migration was a risk factor for psychosis in a Dutch study. ${ }^{30}$ In a systematic review, Shaw et al found that lower density of the ethnic minority population in the neighbourhood was associated with higher risk of psychopathology. This effect was most consistently found for psychosis and was only tentative for other mental disorders, due to heterogeneity and limited statistical power of the studies examined. ${ }^{31}$

\section{AIMS OF THE CURRENT STUDY}

In the current study, we want to further explore the relationship between migration and psychopathology, concentrating on social factors. We aim to investigate the associations between psychotic symptoms and mood symptoms on the one hand and discrimination, social defeat and social support on the other. As the association between social factors and psychopathology may be subgroup-specific, we focus on one ethnic group: the Moroccan-Dutch population. This population is relatively hard to reach for researchers and mental healthcare workers. A previous population-based study in several ethnic groups in the Netherlands reported response rates of $30.2 \%$ for Dutch participants compared with $20.8 \%$ for Moroccan-Dutch participants. ${ }^{17}$ A research report of the Dutch government in the year 2000 states that Moroccan-Dutch patients are underrepresented in the mental healthcare system. ${ }^{32}$ However, since the majority of young Moroccan-Dutch individuals actively visit the website Marokko.nl, we have a unique opportunity to reach this population. 


\section{METHODS AND ANALYSIS}

We will conduct an online survey in a cross-sectional convenience sample of the Moroccan-Dutch population, using a combination of several self-report questionnaires. The survey will run from 15 November 2012 to 1 May 2014.

Our research questions are the following:

1. How often are symptoms of depression and psychosis reported in a cross-sectional sample of young (age 18-35) Moroccan-Dutch participants, measured by self-administered screening questionnaires?

2. Which environmental factors of stress or strain do the Moroccan-Dutch participants report, thereby specifically focusing on social factors such as discrimination, social defeat and social support?

3. What is the association between the symptoms of psychopathology and the reported social factors?

\section{Setting}

We will recruit participants from a unique website, which is visited by the majority of Moroccan-Dutch adolescents: http://www.marokko.nl. This website has been existing for over 10 years. Of all young Moroccan-Dutch people (age 15-35) in the Netherlands, $70 \%$ visit this website regularly of whom $33 \%$ visit the website weekly. ${ }^{33} 34$ Marokko.nl is serving as a national forum board, where everybody can start a discussion and respond to it. With some exceptions, the language in these discussions is Dutch. Discussions are moderated by a trained team of (mostly Moroccan-Dutch) moderators who make sure the website regulations are respected. Only visitors with an account can contribute to the discussion. To set up an account, one has to create a pseudonym and answer some questions on gender and age. This pseudonym is shown when creating or replying to a discussion. Also, the account is connected to a personal email box; this 'personal message' system is available within the site. Because the pseudonyms guarantee anonymity, members feel free to share very personal information in the forum discussions. This includes personal information about sensitive topics like sickness and health, (arranged) marriages, pregnancy and abortion. Although mental health problems are generally a taboo in the Moroccan-Dutch population, on this website many discussions cover this subject. Apparently, there is a need for a platform to discuss these issues in this community.

Despite their need for discussing mental health issues, the Moroccan-Dutch population is under-represented in preventive programmes on mental healthcare. On the Marokko.nl website, psychiatric problems are discussed, but no professional help is offered. In 2012, we therefore created an add-on to the website about mental health. This mental health domain of Marokko.nl is called http://www.ziekofbezeten.marokko.nl ('ziek of bezeten' means: being ill or being possessed). Within this domain, we supply information about psychiatric disorders, self-tests for depression and substance use, and email and chat contact with mental healthcare workers or specially trained Imams. ${ }^{35}$ Our research survey is nested within ziekofbezeten.nl. For a schematic overview of the online environment see figure 1.

\section{Participants and recruitment}

The participants in this study will be recruited from the Moroccan-Dutch population.

Inclusion criteria for this study are:

At least one of the parents is born in Morocco.

Having sufficient knowledge of the Dutch language.

Having Internet access and being a visitor to the website marokko.nl.

Exclusion criterion is:

Age younger than 18 years.

Recruitment takes place online, using the website Marokko.nl. We will recruit participants in several ways, which are listed below and are shown in figure 2. There are three main recruitment routes that lead participants to our survey:

1. Advertisement via banners on Marokko.nl.

2. Via an invitation at the end of a depression self-test on the ziekofbezeten.marokko.nl domain: after filling
Figure 1 Online environment of the study.

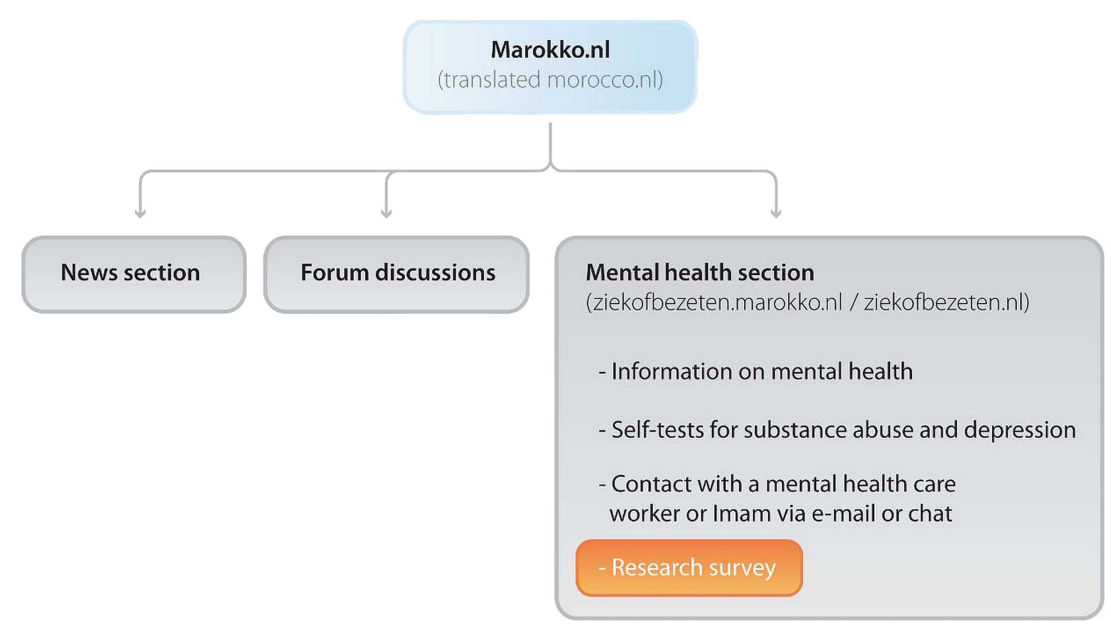


Figure 2 Recruitment strategy and survey design. K10, The Kessler Psychological Distress Scale; PQ-16, The Prodromal Questionnaire-16.

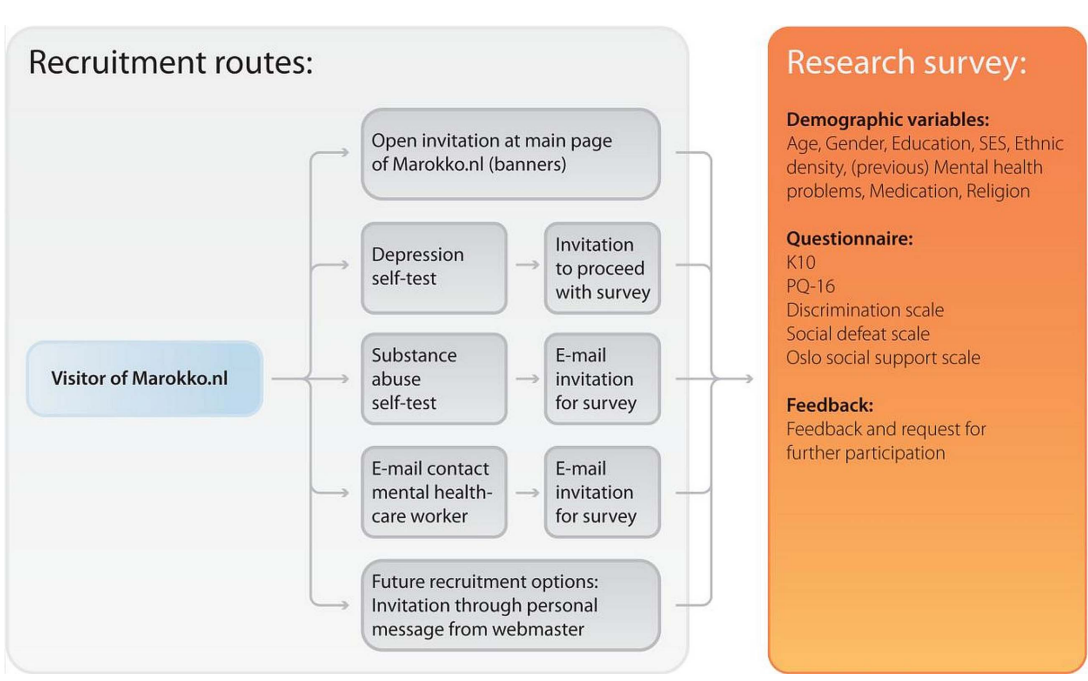

out the depression self-test, people will be asked to participate in the survey.

3. In several places on the website ziekofbezeten.nl, visitors who are interested in participating in the study have the opportunity to 'opt-in' for research and leave an email address.

Should these recruitment routes not result into a sufficient number of participants, additional forms of recruitment can be deployed:

4. Via the 'personal message' function (a marokko.nl linked email service), a random subset of the registered users can be asked to participate.

5. Contributors of several relevant forum discussions can be approached via 'personal message' and asked to participate.

6. Location of the advertisement of the study can be customised. When for example more women than men are included, the study can specifically be advertised on parts of the website where men are active.

We will track the route via which participants were recruited (anonymously), so that we can analyse the various recruitment strategies and compare the participant characteristics between these recruitment strategies.

\section{Procedure}

After inclusion, participants will be asked to fill out an online survey. The first web page will contain information about the study and informed consent. When informed consent is given, the next page will show the survey. The survey consists of questions on depressive and psychotic symptoms, discrimination, social defeat, social support and baseline demographics. Completing all questions will take approximately $10 \mathrm{~min}$. Furthermore, we will ask the participants if we can approach them for further research at a later time. The last page will provide feedback to the participants on the outcome of the questionnaires they filled out. When scores for psychopathology are high, the advice to contact the general practitioner will be given and addresses of mental healthcare organisations are provided.

\section{Measurements and instruments}

We will ask for demographic variables, as listed in table 1. As a measurement of ethnic density, we ask for the first four digits of the postal code, which provides us with enough information to connect to a certain area or neighbourhood without conflicting with the participants' anonymity.

The main part of our online survey consists of a combination of five short questionnaires measuring psychopathology and social factors, which are listed in table 2.

\begin{tabular}{|c|c|}
\hline $\begin{array}{l}\text { Demographic } \\
\text { variables }\end{array}$ & Operationalisation \\
\hline Age & Years \\
\hline Gender & Male/female \\
\hline Ethnicity & $\begin{array}{l}\text { Country of birth, country of birth } \\
\text { parents }\end{array}$ \\
\hline Age of migration & If applicable \\
\hline Ethnic density & Postal code (first 4 figures) \\
\hline $\begin{array}{l}\text { Previous mental } \\
\text { healthcare }\end{array}$ & If yes: diagnosis \\
\hline $\begin{array}{l}\text { Previous/current } \\
\text { medication }\end{array}$ & (free text words) \\
\hline $\begin{array}{l}\text { Social economic } \\
\text { status }\end{array}$ & Income \\
\hline Education & (free text words) \\
\hline Religion & $\begin{array}{l}\text { How important is religion for you? } \\
\text { (Likert scale) }\end{array}$ \\
\hline Substance use & $\begin{array}{l}\text { First } 3 \text { questions of the Drug Use } \\
\text { Disorders Identification Test } \\
\text { (DUDIT)+question on kind of } \\
\text { substance used }\end{array}$ \\
\hline
\end{tabular}




\section{Table 2 Questionnaires}

\begin{tabular}{|c|c|c|c|}
\hline Trait & Questionnaire & Items & $\begin{array}{l}\text { Time } \\
\text { (min) }\end{array}$ \\
\hline $\begin{array}{l}\text { Depressive } \\
\text { symptoms }\end{array}$ & K10 & 10 & 2 \\
\hline $\begin{array}{l}\text { Psychotic } \\
\text { symptoms }\end{array}$ & PQ-16 & 16 & 2 \\
\hline Discrimination & Discrimination scale & 22 & 2 \\
\hline Social defeat & Social defeat scale & 16 & 3 \\
\hline \multirow[t]{2}{*}{ Social support } & $\begin{array}{l}\text { Oslo social support } \\
\text { questionnaire }\end{array}$ & 3 & 1 \\
\hline & $\begin{array}{l}\text { Total time (including } \\
\text { demographics) }\end{array}$ & & 10 \\
\hline
\end{tabular}

The questionnaires are further described below. Table 3 gives an example of questions for each questionnaire.

\section{Psychopathology—mood symptoms}

The Kessler Psychological Distress Scale $(\mathrm{K} 10)^{36}$ is a short questionnaire measuring mood and anxiety symptoms. It contains 10 items on a 5-point Likert scale. This scale has previously been tested for the validity in the Dutch language $^{37}$ and for online self-administration. ${ }^{38}$ Furthermore, it has previously been used in a migrant population in the Netherlands. ${ }^{39}$

\section{Psychopathology—psychotic symptoms}

The Prodromal Questionnaire-16 (PQ-16) ${ }^{41}$ is a short version of the Prodromal Questionnaire. ${ }^{40}$ It is a selfreport screening instrument for psychosis risk, with 16 true/false statements. The instrument has been developed and tested for validity in the Dutch language. ${ }^{41}$ Although this instrument has not been specifically validated in Moroccan-Dutch participants, the sample in which it was studied in the previous research was ethnically diverse. $^{42} 43$

\section{Social factors-perceived discrimination}

Discrimination is measured with a combination of two subscales: the 'everyday discrimination scale' and the 'major experiences of discrimination scale'. ${ }^{44-46}$ The instrument showed adequate results in the appraisal of a review by Bastos et $a l^{47}$ The translation we use was previously used in the Dutch MIGROUP study (an add-on protocol to the GROUP-study). ${ }^{48}$

\section{Social factors-social support}

The Oslo Social Support Questionnaire was designed by Dalgard et al. ${ }^{49-51}$ It consists of only three questions and was the instrument of choice for social support on an expert meeting where common instruments for mental disorders for European population studies called 'EUROHIS' were chosen. ${ }^{52}$ A Dutch translation of the instrument is available.

\section{Social factors-social defeat}

The most widely used instrument for measuring social defeat is the Social Defeat Scale, designed by Gilbert and Allan. $^{29} 53$ It is a 16-item self-report scale. This instrument was also included in the MIGROUP proto$\mathrm{col}^{48}$ and is therefore available in Dutch.

\section{Sample size calculation}

We based the power calculations on two associations we are investigating in our study: (1). the association between discrimination and depression and (2). The association between discrimination and psychosis.

1. The power calculation for the association between depression and discrimination is based on the study by van Dijk et $a .^{24}$ In this study, around $50 \%$ of the 153 Moroccan-Dutch and 199 Turkish-Dutch participants experienced discrimination. In order to be able to detect an association with an effect size measured as an odds ratio (OR) of at least 2, the sample size per group (with and without discrimination) is 182. Based on this association, inclusion should reach a minimum of 400 participants.

2. The power calculation for detecting the association between perceived discrimination and psychotic symptoms (delusional hallucination) was based on Janssen et $a l^{21}$ This study differs from our study because it has a longitudinal design and it also includes Dutch inhabitants, not only migrants. The similarity between both studies is that they both take place in the general (healthy) population. Based on this study, for an $\alpha=0.05$ (two-sided 0.025 ) and $\beta=0.20$

Table 3 Question examples

\begin{tabular}{|c|c|c|}
\hline Questionnaire & Question example & Scale \\
\hline K10 & $\begin{array}{l}\text { During the last month, how often did you feel tired out for no good } \\
\text { reason? }\end{array}$ & 0 -not at all...4-always \\
\hline$P Q-16$ & I have seen things that other people apparently cannot see & True-untrue \\
\hline Discrimination scale & $\begin{array}{l}\text { How often do you experience one of the following types of } \\
\text { discrimination: You are being scoffed at or threatened? }\end{array}$ & 0 -never...3-often \\
\hline Social defeat scale & I feel that I have not made it in life & 0 -not at all...4-always \\
\hline $\begin{array}{l}\text { Oslo social support } \\
\text { questionnaire }\end{array}$ & $\begin{array}{l}\text { How many people are so close to you that you can count on them if } \\
\text { you have serious personal problems? }\end{array}$ & 0 -none...4-six or more \\
\hline
\end{tabular}


(power 80\%) to detect an association with an OR of at least $2, \mathrm{~N}$ had to be at least over 864 participants.

Based on the power calculation for the association between discrimination and psychosis, we aim to include 1000 participants.

\section{Data analysis}

Descriptive statistics

We will describe the sociodemographic variables in our sample and will compare them with those of other studies on psychopathology with Moroccan-Dutch participants. We will investigate the association between social factors (independent variables) and psychopathology (dependent variable) and we correct for relevant sociodemographic variables (confounding variables). The dependent variable psychopathology will be divided into psychotic symptoms and psychological distress (depressive and anxiety symptoms). Using cut-off scores for the specific questionnaires, we consider psychopathology as a binary variable (yes/no psychotic disorder; yes/no psychological distress)

\section{Univariate analysis}

Association between social factors and psychopathology will first be described in percentages, subdivided by sociodemographic variables (eg, gender, age, socioeconomic status and ethnicity). We will use $\chi^{2}$ test for categorical and test for continuous variables to identify significant associations between these variables. We will take gender differences in our sample into account in our analysis, since previous studies on the Moroccan-Dutch population have shown large differences in the psychopathology rates between men and women. $^{1417}$

\section{Multivariate analysis}

After univariate analysis, we will use a regression model (possibly Poisson regression) to investigate the association between psychopathology and the social factors, correcting for confounders. The exact regression model we will choose is partly dependent on the incidence of psychopathology in our sample. We consider the Poisson regression model, because we expect that the occurrence of psychopathology will not be high in our nonclinical sample.

\section{Ethics and dissemination}

\section{Informed consent and data security}

When entering the survey, participants are asked for informed consent. They can give their consent by checking a box. In addition, participants will be asked to check a box to confirm that their age is above 18 . When both boxes are checked, participants can click on 'next' and the first page of the survey is displayed. A unique research identification number will then be created for each participant, which is used for data filing and handling. All recorded personal information (like pseudonym on the website, name or email address) will be coded. IP-addresses will not be recorded.

For the online questionnaire, we use the service of Qualtrics. ${ }^{54}$ In this online service we can design the entire survey and link it to the ziekofbezeten-domain of Marokko.nl (so it can be opened from this website). They guarantee good safety measurements for data storage and handling. For online data transport, the safety is comparable with Internet banking. The researchers remain the owner of the data and can download it for analysis. The user account of the researcher is secured by username and password. ${ }^{55}$

\section{Ethical considerations}

The Medical Ethical Committee of the UMCG has assessed the study protocol and has judged that the study could be conducted without their approval.

\section{Dissemination}

We aim to present the study results at conferences and in one or more scientific publications in peer-reviewed journals. After publication, results of the study will also be published on ziekofbezeten.nl, to inform study participants and other interested people about the results.

\section{DISCUSSION}

This study protocol is a result of new possibilities the Internet creates for epidemiological research. We describe an online survey in the Moroccan-Dutch population, a target group that is hard to reach for researchers and healthcare workers through traditional means, but which is very actively participating in a range of social exchanges on the website Marokko.nl. The methodology of online research is rather new in the psychiatric epidemiology and has many advantages. Research within an online community offers the possibility to reach large numbers of the study population with relatively simple means at affordable costs. ${ }^{56} 57$ Online questionnaires have a more structured format, therefore reducing the risk of skipping questions or making errors by the participants. ${ }^{58}$ Questions can be customised, based on previous answers, saving time for the participant. Furthermore, there is no data entry by the researcher, which saves time and reduces data entry errors. $^{59}$ Like in our study, online recruitment can provide unique access to groups that are otherwise difficult to reach. 565960

An important aspect of this study is that it is designed in close collaboration with the Marokko.nl gatekeepers, who are familiar with or are a part of the MoroccanDutch target population. This enhances the survey design, reduces non-response and secures efficient recruitment strategies within the website.

Although the Internet creates new and exciting possibilities in epidemiological research, there are also new challenges and possible limitations. With online research, recruiting a probability sample is difficult or 
even impossible and response rates cannot always be calculated. $^{60}$

In a non-probability or convenience sample, there is a possible risk of selection bias, which is one of the major limitations of our study. Recruitment via a convenience sample is entirely dependent on people who are willing to volunteer. Therefore, the probability that people who, for example, fear stigmatisation are less likely to participate in research focusing on mental illness. However, this may be partly countered by the fact that the Internet survey allows participants to stay anonymous. This is supported by the fact that mental illnesses are frequently and openly discussed on Marokko.nl.

However, non-probability or convenience samples can also generate important information. Two studies investigated ecstasy use with different sampling strategies to compare probability versus non-probability samples. ${ }^{61} 62$ They concluded that the two samples were to a great extent comparable in terms of demographic and drug use characteristics. The samples differed slightly on employment status, ${ }^{61} 62$ recent use of drugs other than ecstasy and how the ecstasy was obtained. ${ }^{62}$ The authors suggest that the differences were due to different recruitment strategies. Another study used probability and nonprobability samples in a study of elderly patients with end-stage renal disease and their spouses. Although there were some differences on religion and ethnicity, most demographic characteristics were comparable. ${ }^{63}$ In our design, we recruit a convenience sample within a well-described population of which the overall size within the population is known. We will therefore be able to compare the demographic characteristics in our sample with the characteristics of the entire Moroccan-Dutch population.

An important limitation of our recruitment strategy is that people with psychological symptoms may be more interested in participating in the study, and may thus be over-represented. More specifically, recruitment via the depression self-test might encourage people with depressive symptoms to participate in particular. By using and recording different recruitment methods (such as the depression self-test and advertisement on Marokko.nl), we can investigate the effects of the recruitment strategy on the outcome variables. Depending on these differences, we might need to correct for it in our analyses.

Another possible limitation is our use of a crosssectional design, which may show associations between variables, but does not reveal causal and temporal relations. However, the results of this study will serve as the basis for future research, in which temporal relations can be more closely studied. We will ask participants' consent to approach them at a later moment. We consider performing a follow-up measurement with the same design and instruments. If we are able to reach enough participants, we can create a prospective cohort.

Using only self-report information could be another possible limitation of the study. We have no other source to check the demographic variables, the notification of symptoms and the absence or presence of social factors. This may lead to participants exaggerating (or underreporting) their symptoms in order to see how this influences the feedback they are given. However, earlier research suggests that the anonymity of online selfreport questionnaires can also result in more open and honest answers to sensitive questions compared with questionnaires that are used by an interviewer, ${ }^{58-60}$ and there is no risk for interviewer bias. ${ }^{59}$

Acknowledgements The authors would like to thank Lude Franke for his help in designing the figures.

Contributors RS conceptualised and initiated the website ziekofbezeten.nl MvdB and RS designed the study. MvdB wrote the manuscript. LvdK and RS contributed to, and critically revised the manuscript. All the authors read and approved the final version of the manuscript.

Funding The website ziekofbezeten.nl was built with financial support of the 'Innovatiefonds Zorgverzekeraars', the 'Skanfonds' and 'Stichting Voorzorg Utrecht'.

Competing interests None.

Ethics approval Medical Ethical Committee of the University Medical Center Groningen.

Provenance and peer review Not commissioned; externally peer reviewed.

Open Access This is an Open Access article distributed in accordance with the Creative Commons Attribution Non Commercial (CC BY-NC 3.0) license, which permits others to distribute, remix, adapt, build upon this work noncommercially, and license their derivative works on different terms, provided the original work is properly cited and the use is non-commercial. See: http:// creativecommons.org/licenses/by-nc/3.0/

\section{REFERENCES}

1. Cantor-Graae E, Pedersen CB. Full spectrum of psychiatric disorders related to foreign migration: a Danish population-based cohort study. JAMA Psychiatry 2013;70:427-35.

2. van Os J, Kenis G, Rutten BP. The environment and schizophrenia. Nature 2010;468:203-12.

3. Wichers M, Schrijvers D, Geschwind N, et al. Mechanisms of gene-environment interactions in depression: evidence that genes potentiate multiple sources of adversity. Psychol Med 2009;39:1077-86

4. Kendler KS. The dappled nature of causes of psychiatric illness: replacing the organic-functional/hardware-software dichotomy with empirically based pluralism. Mol Psychiatry 2012;17:377-88.

5. McGrath JJ, Lawlor DA. The search for modifiable risk factors for schizophrenia. Am J Psychiatry 2011;168:1235-8.

6. Bourque F, van der Ven E, Malla A. A meta-analysis of the risk for psychotic disorders among first- and second-generation immigrants. Psychol Med 2011;41:897-910.

7. Cantor-Graae E, Selten JP. Schizophrenia and migration: a meta-analysis and review. Am J Psychiatry 2005;162:12-24.

8. Harrison G. Searching for the causes of schizophrenia: the role of migrant studies. Schizophr Bull 1990;16:663-71.

9. Selten JP, Cantor-Graae E. Social defeat: risk factor for schizophrenia? Br J Psychiatry 2005;187:101-2.

10. Swinnen SG, Selten JP. Mood disorders and migration: meta-analysis. Br J Psychiatry 2007;190:6-10.

11. Missinne S, Bracke P. Depressive symptoms among immigrants and ethnic minorities: a population based study in 23 European countries. Soc Psychiatry Psychiatr Epidemiol 2012;47:97-109.

12. Levecque K, Lodewyckx I, Vranken J. Depression and generalised anxiety in the general population in Belgium: a comparison between native and immigrant groups. J Affect Disord 2007;97:229-39.

13. http://statline.cbs.nl/StatWeb/publication/?VW=T\&DM=SLNL\& $\mathrm{PA}=37325 \& \mathrm{D} 1=\mathrm{a} \& \mathrm{D} 2=0$ \&D3=0\&D4=0\&D5=0-1,3,137,152,220 $237 \& D 6=\mid \& H D=130312-1304 \& H D R=T \& S T B=G 1, G 2, G 3, G 4, G 5$

14. Selten JP, Sijben N. First admission rates for schizophrenia in immigrants to The Netherlands. The Dutch National Register. Soc Psychiatry Psychiatr Epidemiol 1994;29:71-7. 
15. Veling W, Selten JP, Veen N, et al. Incidence of schizophrenia among ethnic minorities in the Netherlands: a four-year first-contact study. Schizophr Res 2006;86:189-93.

16. Selten JP, Laan W, Kupka R, et al. Risk of psychiatric treatment for mood disorders and psychotic disorders among migrants and Dutch nationals in Utrecht, The Netherlands. Soc Psychiatry Psychiatr Epidemiol 2012;47:271-8.

17. de Wit MA, Tuinebreijer WC, Dekker J, et al. Depressive and anxiety disorders in different ethnic groups: a population based study among native Dutch, and Turkish, Moroccan and Surinamese migrants in Amsterdam. Soc Psychiatry Psychiatr Epidemiol 2008;43:905-12.

18. Ødegaard O. Emigration and insanity: a study of mental disease among Norwegian-born population in Minnesota. Acta Psychiatr Scand 1932;7:1-206.

19. Selten JP, Cantor-Graae E, Slaets J, et al. Odegaard's selection hypothesis revisited: schizophrenia in Surinamese immigrants to The Netherlands. Am J Psychiatry 2002;159:669-71.

20. Morgan C, Charalambides M, Hutchinson G, et al. Migration, ethnicity, and psychosis: toward a sociodevelopmental model. Schizophr Bull 2010;36:655-64.

21. Janssen I, Hanssen M, Bak M, et al. Discrimination and delusional ideation. Br J Psychiatry 2003;182:71-6.

22. Veling W, Selten JP, Susser E, et al. Discrimination and the incidence of psychotic disorders among ethnic minorities in The Netherlands. Int J Epidemiol 2007;36:761-8.

23. Karlsen S, Nazroo JY, McKenzie K, et al. Racism, psychosis and common mental disorder among ethnic minority groups in England. Psychol Med 2005;35:1795-803.

24. van Dijk TK, Agyemang $\mathrm{C}$, de Wit M, et al. The relationship between perceived discrimination and depressive symptoms among young Turkish-Dutch and Moroccan-Dutch. Eur J Public Health 2011;21:477-83.

25. Wamala S, Bostrom G, Nyqvist K. Perceived discrimination and psychological distress in Sweden. Br J Psychiatry 2007;190:75-6.

26. Gee GC, Spencer M, Chen J, et al. The association between self-reported racial discrimination and 12-month DSM-IV mental disorders among Asian Americans nationwide. Soc Sci Med 2007;64:1984-96.

27. Cantor-Graae E. The contribution of social factors to the development of schizophrenia: a review of recent findings. Can $J$ Psychiatry 2007;52:277-86.

28. Kuo BC, Chong V, Joseph J. Depression and its psychosocial correlates among older Asian immigrants in North America: a critical review of two decades' research. J Aging Health 2008;20:615-52.

29. Gilbert $P$, Allan $S$. The role of defeat and entrapment (arrested flight) in depression: an exploration of an evolutionary view. Psychol Med 1998;28:585-98.

30. Veling $\mathrm{W}$, Hoek $\mathrm{H}$, Selten $\mathrm{J}$, et al. Age at migration and future risk of psychotic disorders among immigrants in the Netherlands: a 7-year incidence study. Am J Psychiatry 2011;168:1278-85.

31. Shaw RJ, Atkin K, Bécares L, et al. Impact of ethnic density on adult mental disorders: narrative review. $\mathrm{Br} J$ Psychiatry 2012;201:11-19.

32. Raad voor de Volksgezondheid en Zorg, Trimbos-instituut Allochtone cliënten en geestelijke gezondheidszorg (achtergrondstudie bij Interculturalisatie van de gezondheidszorg). Report No: 99/22, 2000.

33. Verheggen PP, Moha AA, Gomes C, et al. 'Beraken van Nieuwe Nederlanders'; Bereik van cultuurgebonden media. Report No: L1166, 2007.

34. http://www.urbanconnect.nl/index.php?nav=static\&pagina=Marokko.n

35. van de Beek $\mathrm{MH}$, van der Krieke L, Schoevers RA. Online menta health platform for moroccan-dutch in the Netherlands. Psychiatr Serv 2013;64:1178.

36. Kessler RC, Andrews G, Colpe LJ, et al. Short screening scales to monitor population prevalences and trends in non-specific psychological distress. Psychol Med 2002;32:959-76.

37. Donker T, Comijs $\mathrm{H}$, Cuijpers $\mathrm{P}$, et al. The validity of the Dutch K10 and extended K10 screening scales for depressive and anxiety disorders. Psychiatry Res 2010;176:45-50.

38. Donker T, van Straten A, Marks I, et al. Brief self-rated screening for depression on the Internet. J Affect Disord 2010;122:253-9.

39. Fassaert T, De Wit MA, Tuinebreijer WC, et al. Psychometric properties of an interviewer-administered version of the Kessler
Psychological Distress scale (K10) among Dutch, Moroccan and Turkish respondents. Int J Methods Psychiatr Res 2009;18:159-68.

40. Loewy RL, Bearden CE, Johnson JK, et al. The prodromal questionnaire (PQ): Preliminary validation of a self-report screening measure for prodromal and psychotic syndromes. Schizophr Res 2005;79:117-25.

41. Ising HK, Veling W, Loewy RL, et al. The validity of the 16-item version of the Prodromal Questionnaire (PQ-16) to screen for ultra high risk of developing psychosis in the general help-seeking population. Schizophr Bull 2012;38:1288-96.

42. Rietdijk J, Dragt S, Klaassen $\mathrm{R}$, et al. A single blind randomized controlled trial of cognitive behavioural therapy in a help-seeking population with an At Risk Mental State for psychosis: the Dutch Early Detection and Intervention Evaluation (EDIE-NL) trial. Trials 2010;11:30.

43. Rietdijk J, Klaassen $\mathrm{R}$, Ising $\mathrm{H}$, et al. Detection of people at risk of developing a first psychosis: comparison of two recruitment strategies. Acta Psychiatr Scand 2012;126:21-30.

44. Kessler RC, Mickelson KD, Williams DR. The prevalence, distribution, and mental health correlates of perceived discrimination in the United States. J Health Soc Behav 1999;40:208-30.

45. Krieger N, Smith K, Naishadham D, et al. Experiences of discrimination: validity and reliability of a self-report measure for population health research on racism and health. Soc Sci Med 2005;61:1576-96.

46. Williams DR, Yan Yu, Jackson JS, et al. Racial differences in physical and mental health. J Health Psychol 1997;2:335-51.

47. Bastos JL, Celeste RK, Faerstein E, et al. Racial discrimination and health: a systematic review of scales with a focus on their psychometric properties. Soc Sci Med 2010;70:1091-9.

48. Selten JP, Havenaar JM. Migratie en Niet-Affectieve Psychose; Add-on study bij protocol 'kwetsbaarheid en veerkracht bi niet-affectieve psychose', 2004

49. Dowrick C, Casey P, Dalgard O, et al. Outcomes of Depression International Network (ODIN). Background, methods and field trials. ODIN Group. Br J Psychiatry 1998;172:359-63.

50. Dalgard OS, Thapa SB, Hauff E, et al. Immigration, lack of control and psychological distress: findings from the Oslo Health Study. Scand J Psychol 2006;47:551-8.

51. Syed H, Dalgard O, Dalen I, et al. Psychosocial factors and distress: a comparison between ethnic Norwegians and ethnic Pakistanis in Oslo, Norway. BMC Public Health 2006;6:182.

52. Meltzer $\mathrm{H}$. Development of a common instrument for mental health In: Nosikov A, Gudex C, eds. EUROHIS: developing common instruments for health surveys. Amsterdam: IOS Press, 2003.

53. Taylor PJ, Gooding P, Wood AM, et al. The role of defeat and entrapment in depression, anxiety, and suicide. Psychol Bull 2011;137:391-420.

54. http://www.qualtrics.com

55. Hite K. Qualtrics Security White Paper, Why should I trust Qualtrics with my sensitive data?. Report No.: version 2.0, 2011.

56. Wright KB. Researching Internet based populations: advantages and disadvantages of online survey research, online questionnaire authoring software packages, and web survey services. J Comput Mediated Commun 2006;10:00.

57. Ekman A, Litton JE. New times, new needs; e-epidemiology. Eur J Epidemiol 2007;22:285-92.

58. van Gelder MM, Bretveld RW, Roeleveld N. Web-based questionnaires: the future in epidemiology? Am J Epidemiol 2010:172:1292-8.

59. Rhodes SD, Bowie DA, Hergenrather KC. Collecting behavioural data using the world wide web: considerations for researchers. $J$ Epidemiol Community Health 2003;57:68-73.

60. Van Selm M, Jankowski N. Conducting online surveys. Qual Quantity 2006;40:435-56.

61. Topp $L$, Barker B, Degenhardt $L$. The external validity of results derived from ecstasy users recruited using purposive sampling strategies. Drug Alcohol Depend 2004;73:33-40.

62. Miller PG, Johnston J, Dunn M, et al. Comparing probability and non-probability sampling methods in ecstasy research: implications for the internet as a research tool. Subst Use Misuse 2010;45:437-50.

63. Feild L, Pruchno RA, Bewley J, et al. Using probability vs. nonprobability sampling to identify hard-to-access participants for health-related research. J Aging Health 2006;18:565-83. 